\title{
A ANTERIORIDADE ONTOLÓGICA DA INDIVIDUAÇÃO: PRIMEIRO ESTUDO
}

\section{SUSIANE KREIBICH' ${ }^{1}$ E THIAGO SOARES LEITE ${ }^{2}$}

RESUMO: O artigo investiga a teoria do princípio de individuação formulada por João Duns Scotus, a qual fornece elementos para a compreensão do que torna algo indivíduo e o diferencia dos demais. Para Duns Scotus, o indivíduo é constituído ontologicamente por algo positivo inerente à substância singular. Ainda que os acidentes acompanhem a substância, estes não podem ser a causa da sua individuação, pois são posteriores a ela. Duns Scotus nega que algo que acompanhe ou seja posterior ao indivíduo seja a sua causa, pois esta deve ser intrínseca e positiva ao indivíduo. Ou seja, não é possível que aquilo que torna algo este indivíduo lhe seja ontologicamente posterior no ser. $\mathrm{O}$ artigo busca mostrar que 1) há distinção entre o que, contemporaneamente, podemos denominar de indivíduo e de identidade e 2) há anterioridade ontológica do indivíduo em relação à identidade.

PALAVRAS-CHAVE: Indivíduo. Identidade. Metafísica. Duns Scotus.

ABSTRACT: The article investigates the theory of the principle of individuation formulated by John Duns Scotus, which provides elements for understanding what makes something individual and differentiates it from others. For Duns Scotus, the individual is ontologically constituted by something positive inherent to the singular substance. Even if accidents accompany the substance, these may not be the cause of their individuation, as they are subsequent to it. Duns Scotus denies that something that accompanies or is posterior to the individual is its cause, because this must be intrinsic and positive to the individual. That is, it is not possible that what makes something this individual is ontologically posterior in the being. The article seeks to show that 1) there is distinction between what, contemporaneously, we can call individual and identity and 2) there is an ontological anteriority of the individual in relation to the identity.

KEYWORDS: Individual. Identity. Metaphysics. Duns Scotus.

$\mathrm{O}$ artigo tem como objetivo analisar a teoria do princípio de individuação formulada por João Duns Scotus (1265/6-1308), mostrando os argumentos scotistas a favor da anterioridade ontológica da individuação em relação à identidade. A investigação aqui desenvolvida é o primeiro de quatro estudos ${ }^{3}$ através dos quais buscamos analisar se as teorias investigadas, na

\footnotetext{
1 Mestre em Ciências Humanas pela Universidade Federal da Fronteira Sul (UFFS). E-mail: susikreibich @gmail.com.

2 Professor Adjunto de Filosofia da Universidade Federal da Fronteira Sul (UFFS). Doutor em Filosofia pela Pontifícia Universidade Católica do Rio Grande do Sul (PUC-RS). E-mail: thiago.leite@uffs.edu.br.

3 Tais estudos são resultado da nossa pesquisa de mestrado realizada junto ao Programa de Pós-graduação Interdisciplinar em Ciências Humanas da Universidade Federal da Fronteira Sul - Campus Erechim. A pesquisa
} 
compreensão da noção de sujeito, ${ }^{4}$ pressupõem uma ontologia que identifica uma estrutura do ser individual ou se conseguem explicá-lo apenas como um constructo, por exemplo, fundado na linguagem.

Ao longo dos estudos, trabalhamos com dois conceitos-chave: indivíduo e identidade, buscando mostrar que constituição ${ }^{5}$ de indivíduo e constituição de identidade possuem conteúdos conceituais distintos e indicam aspectos diferenciados de um mesmo sujeito. Constituição de indivíduo está vinculada à individuação, i.e., ao princípio que torna cada indivíduo único e irrepetível. A constituição de indivíduo é ontologicamente anterior ${ }^{6}$ à constituição de identidade. Portanto, primeiramente há o substrato ontológico denominado indivíduo ${ }^{7}$ e a partir dele é possível construir-se as identidades.

Por constituição de identidade, entendemos como o processo de identificação do indivíduo com os modelos identitários oferecidos pelo contexto sociocultural. ${ }^{8}$ Ou seja, os modelos de identidades são fornecidos pelo contexto sociocultural, e o indivíduo investe naqueles que lhe são relevantes. As identidades são resultado do investimento psíquico do indivíduo nas posições que os discursos de identidade do seu contexto sociocultural the oferecem. As identidades passam a ser relevantes para o indivíduo por meio da linguagem e dos sistemas simbólicos pelos quais são representadas. ${ }^{9}$

As identidades não são fixas e unificadas, podendo ser transformadas de acordo com a importância que o sujeito dá àquilo que o mundo lhe oferece. Há o investimento psíquico do indivíduo naqueles modelos identitários que lhe aprazem enquanto estes lhe são relevantes. Ao passo que algum modelo deixe de ser relevante, há a possibilidade de outros modelos serem tomados como referenciais. Não há uma identidade fixa ao longo da existência, mas há identidades diferentes, seja concomitantemente, seja em momentos diferentes.

foi realizada com apoio da Coordenação de Aperfeiçoamento de Pessoal de Nível Superior - Brasil (CAPES) Código de Financiamento 001.

${ }^{4}$ Há muitos termos para referenciar o ser humano, e cada um deles evoca um conteúdo conceitual específico. Sendo assim, utilizamos o termo "sujeito" de modo genérico.

${ }^{5}$ Utilizamos o termo "constituição" no sentido genérico.

${ }^{6}$ A anterioridade ontológica é a anterioridade que ocorre na estrutura do ser. Esta difere-se da anterioridade temporal, a qual é a anterioridade que ocorre no tempo linear. Nesse sentido, a anterioridade ontológica não implica em anterioridade temporal. Algo que é ontologicamente anterior pode ser temporalmente concomitante.

${ }^{7}$ Indivíduo é aquilo que possui unidade indivisível, ou seja, unidade numérica, a qual não pode ser dividida sem que o indivíduo seja corrompido e destruído.

${ }^{8}$ Seguimos o conceito de identidade apresentado em WOODWARD, 2011, pp.7-72.

${ }^{9}$ Os sucessíveis processos de identificação possibilitam ao indivíduo construir as suas identidades a partir de modelos identitários que lhe são oferecidos no seu contexto sociocultural, por exemplo: ser mulher, ser homem, ser intelectual, ser guerreiro etc. Esses modelos não são fixos, pois são definidos historicamente e são produzidos no tempo. 
Isso posto, neste primeiro estudo, como já dito, nos voltamos à teoria do princípio de individuação formulada por Duns Scotus. ${ }^{10}$ Encontramos no pensamento scotista a formulação de um princípio de individuação que estabelece uma nova diretriz na tradição filosófica ocidental, uma vez que confere maior estatuto ontológico ao singular. ${ }^{11}$ Duns Scotus formula um princípio de individuação intrínseco à substância e comum a todas as substâncias criadas, apresentando pela primeira vez, até onde se sabe, um princípio de individuação pensado como estrutura. O princípio de individuação scotista não reduz o indivíduo a uma essência que o determina, mas fornece a estrutura que permite ao indivíduo possibilidades de ser.

Um princípio de individuação não deve fornecer apenas uma definição de individualidade, mas deve determinar o estatuto ontológico da mesma, uma vez que responde a três questões fundamentais para tal: 1) há uma entidade individualizante que constitui o indivíduo ou isso é apenas uma construção mental?;2) se há uma entidade individualizante, o que ela é?; 3) como são distintos o indivíduo e os demais componentes do indivíduo? ${ }^{12} \mathrm{O}$ princípio de individuação scotista responde as três questões, pois prova que a entidade individualizante não é apenas uma construção mental, mas é algo no indivíduo. Também afirma o que é a entidade individualizante e apresenta como são distintos o indivíduo e os componentes do indivíduo, como veremos ao longo deste artigo.

João Duns Scotus formula a sua teoria do princípio de individuação em cinco obras fundamentais, quais sejam: Lectura II, d. 3, q. 1-6; Reportatio II, d. 12, q. 3-8; Ordinatio II, d. 3, p. 1, q. 1-6; Quodlibet, q. 2, art. 1; e Quaestiones super libros Metaphysicorum Aristotelis, VII, q. 13. ${ }^{13}$ Destas, a obra Lectura, II, d. 3, q. 1-6, figura como, até onde se sabe, a primeira formulação de uma teoria da individuação feita por Duns Scotus em sua fase de maturidade. A teoria da individuação da substância material é elaborada a partir das críticas às teorias da individuação dos demais mestres e possui inspiração nas Sentenças de Pedro Lombardo. ${ }^{14}$ A

\footnotetext{
${ }^{10}$ Embora o que nos interessa nesta investigação seja o indivíduo humano, sabemos que o princípio de individuação scotista não é um princípio exclusivo aos seres humanos, mas é um princípio universal aplicado a todas as coisas existentes no mundo. O princípio que individua o ser humano é o mesmo princípio que individua a pedra, por exemplo, diferindo entre eles não o princípio, mas o elemento individuante. O que torna o ser humano, enquanto espécie, distinto das demais espécies existentes no mundo é a estrutura ontológica advinda de sua própria espécie e que recebe o nome de natureza.

${ }^{11}$ Cf. PÉREZ-ESTÉVEZ. 2008, p. 79.

${ }^{12}$ Cf. GRACIA. 1996, p. 231.

${ }^{13}$ Pode-se considerar um sexto texto em que encontramos a discussão sobre o princípio de individuação a questão disputada com o dominicano Guilherme Pedro Godino e publicada por C. STROICK. 1974, pp. 559-608 e que possui por título Utrum materia sit principium individuationis. Nessa questão, Duns Scotus voltar-se-á contra a tese segundo a qual a matéria se constitui como o princípio de individuação. Contudo, como o foco da discussão é a matéria como princípio de individuação, não elencamos esse texto com os outros cincos já citados.

${ }^{14}$ Cf. WOLTER. 2005, p. ix.
} 
discussão acerca da individuação é tratada em seis questões, ${ }^{15}$ as quais correspondem, cada uma, a um candidato ao princípio que individualiza a substância material. ${ }^{16}$

Ao discutir a partir das teorias formuladas pelos demais mestres, Duns Scotus formula a sua própria teoria do princípio de individuação. Há dois conceitos que configuram como o cerne da teoria scotista da individuação: "natureza", formulado na Questão 1; e "diferença individual", formulado na Questão 6. A natureza é o ser quiditativo compartilhado entre os indivíduos pertencentes a uma mesma espécie. Já a diferença individual é uma entidade positiva inerente à substância material e indissociável dela. Ao contrair a natureza, a diferença individual torna algo este ${ }^{17}$ indivíduo.

Embora os dois conceitos-chave da teoria scotista da individuação sejam apresentados nas Questões 1 e 6, as Questões 2, 3, 4 e 5 apresentam elementos que nos permitem compreender o universo conceitual de Duns Scotus. Destas, a Questão 4 apresenta uma discussão que nos é fundamental. Nela, Duns Scotus prova não ser possível que algo ontologicamente posterior à substância a individue, i.e., uma vez que os acidentes são posteriores à substância, não podem ser a causa da individuação. Os acidentes são consequência da individuação, pois é preciso haver a substância singularizada para que existam os acidentes; portanto, os acidentes possuem existência por outro. Os acidentes são o sine qua non da substância. Da mesma maneira, pretendemos mostrar que as identidades acompanham o indivíduo, pois não há indivíduo sem identidades, assim como não há substância sem os seus acidentes. Mas, para haver identidades, é necessário que haja, anteriormente, a individuação.

Para fins metodológicos, trataremos dos principais elementos que configuram a teoria scotista, os quais são discutidos na seguinte ordem: 1) Natureza; 2) Todo acidente é posterior à substância; 3) Diferença individual; e 4) Distinção formal.

\footnotetext{
${ }^{15}$ Há uma sétima questão, em que a pessoalidade dos anjos é, enfim, discutida. Não a consideramos, aqui, como parte da análise por, fundamentalmente, dois motivos: em primeiro lugar, trata-se de uma questão teológica e, assim, foge ao escopo de nosso estudo; em segundo lugar, não encontramos, nessa sétima questão, algum elemento novo na teoria. Antes, encontramos a aplicação da teoria previamente delineada e discutida ao caso dos anjos.

${ }^{16}$ As seis questões encontram-se assim organizadas: A Questão 1 discute se, a partir de sua natureza, a substância material é singular e individual. A Questão 2 indaga se a substância material é individual por algo positivo e intrínseco. A Questão 3 discute se a substância material é individualizada por meio de sua existência atual. A Questão 4 indaga se a quantidade é aquele positivo pelo qual a substância material é um esta, singular e indivisível em partes subjetivas. A Questão 5 discute se é a matéria o que individua a substância material. Por fim, a Questão 6 indaga se a substância material é um indivíduo por meio de uma entidade positiva que determina a natureza a ser esta substância individual.

${ }^{17}$ Como era de hábito de Duns Scotus e de seus contemporâneos, o pronome demonstrativo "este/a" (hic, haec, hoc, em latim) é usado para marcar o singular.
} 


\section{1 - Natureza}

Quando nos deparamos com indivíduos, constatamos que cada um deles possui algo que nos permite diferenciá-lo dos demais. Há multiplicidade no mundo. Ao passo que há a constatação da multiplicidade dos indivíduos, também percebemos que determinado indivíduo possui algo comum com outros indivíduos. Seres humanos, por exemplo, possuem algo comum a partir do qual são considerados pertencentes à mesma espécie. Dito de outra maneira, os indivíduos que pertencem à mesma espécie compartilham algo comum entre si, ou seja, cada singular comunga de algo com os demais da espécie à qual ele pertence.

No medievo, via de regra, o "algo comum" compartilhado entre os indivíduos de uma mesma espécie denomina-se natureza. No universo conceitual scotista, a natureza é uma estrutura ontológica que servirá de base para a individualidade da substância material singular e para a universalidade do conceito, uma vez que é indiferente ${ }^{18}$ a ambos. A natureza serve tanto para o singular, uma vez que é contraída pela diferença individual tornando algo este singular, quanto para o ato do intelecto que, ao apreendê-la, o faz por meio da modalidade da universalidade.

Uma vez que é indiferente, a natureza é uma estrutura que pode estar neste ou naquele indivíduo, não sendo exclusiva a apenas um deles. Por ser uma estrutura ontológica compartilhada entre indivíduos da mesma espécie, a natureza existe na realidade. Portanto, a natureza possui realidade ontológica, pois se encontra no singular.

Por outro lado, embora possua realidade e esteja no singular, a natureza não pode ser algo que apenas determinado indivíduo possua. Se assim o fosse, a própria noção de espécie seria destruída, pois cada indivíduo seria possuidor de uma natureza exclusiva e, consequentemente, cada espécie seria indivíduo. ${ }^{19}$

\footnotetext{
${ }^{18}$ A noção de indiferença do conceito scotista de natureza é resultado da influência da teoria dos universais do filósofo medieval persa Avicena (980-1037). Não é nosso objetivo nos deter na teoria aviceniana dos universais. Porém, cabe saber que em Metaph., V, c. 1, (Van Riet. II, p. 227), Avicena discute sobre as coisas comuns e o ser delas. Ao discutir o conceito de universal, Avicena afirma que a universalidade é intenção no intelecto ao qual não é impossível ser predicado de muitos. O universal é algo diferente daquilo sobre o qual ele recai. O universal enquanto universal é uma só coisa significada dos termos predicados e incide sobre a quididade. Desse modo, com o exemplo da definição de equinidade, Avicena afirma tanto que essa definição está além da definição de universalidade, quanto que a universalidade não está contida na definição de equinidade. A equinidade, quando considerada nela mesma, é indiferente ao universal e ao singular, ou seja, a própria equinidade não é algo senão equinidade. No âmbito da Lectura, o pensamento aviceniano utilizado por Duns Scotus é explicitado em Lect. II, d. 3, p. 1, q. 1, nn. 30-31. Já no âmbito da Ordinatio, em Ord. II, d. 3, p. 1, q. 1, nn. 30-31.

${ }^{19}$ Esse argumento será melhor explorado quando apresentarmos alguns argumentos propostos por Duns Scotus com a finalidade de provar a existência de uma unidade real menor do que a numérica.
} 
O que garante à natureza poder ser replicada é a comunidade. ${ }^{20}$ Por ser uma estrutura ontológica dotada de comunidade, a natureza é capaz de estar em muitos indivíduos, mantendo a unidade da espécie. A unidade da natureza difere-se da unidade numérica ${ }^{21}$ e é denominada unidade real menor do que unidade numérica.

A existência da unidade real menor do que a numérica é discutida na primeira parte da Questão 1. Duns Scotus fundamenta a sua teoria da existência de uma unidade real menor do que a unidade numérica através de sete provas. $^{22}$ Destas nos deteremos em três delas, quais sejam: na quinta, na sexta e na sétima, respectivamente.

Um ato dos sentidos, como o ver, requer um objeto sob alguma unidade real que não a unidade numérica. ${ }^{23}$ Isto quer dizer que, quando um ato dos sentidos, como a visão, recai sob algum objeto, não há discernimento entre o branco visto nesse objeto e o branco visto, posteriormente, em outro objeto, por exemplo. Com outras palavras, o que diferencia as duas ocorrências do branco não é o próprio branco, mas o objeto no qual ele incide. O branco possui uma unidade real que não a unidade numérica, uma vez que a visão não discerne duas brancuras. Se a unidade da brancura fosse a unidade numérica, então a visão discerniria o branco de determinado objeto de todo o branco visto posteriormente. Portanto, há uma unidade real menor do que a numérica.

O gerado é semelhante ao gerador em forma e em natureza. ${ }^{24} \mathrm{O}$ gerado é semelhante ao gerador por uma geração unívoca, isto é, o gerado possui algo comum com aquele que o gerou. Esse algo comum existe na realidade e independe da ação do intelecto que o conhece. $\mathrm{O}$

\footnotetext{
${ }^{20}$ Em Lectura, Duns Scotus utiliza "universalidade na coisa", ao invés do termo "comunidade". Lect. II, d. 3, q. 1, n. 34: "Digo que há tal 'universalidade na coisa' para o que não repugna 'ser universal'. Mas isso não é formalmente o universal [...]”. Já em Ordinatio, o termo "comunidade” é evidenciado em Ord. II, d. 3, p. 1, q. 1, n. 42: “[...] é evidente que a comunidade e a singularidade não estão para a natureza como o ser no intelecto e o ser verdadeiro fora da alma, porque a comunidade convém à natureza fora do intelecto, e, de maneira semelhante, a singularidade, - e a comunidade convém à natureza por si, a singularidade, contudo, convém à natureza por meio de algo na coisa que a contrai; mas a universalidade não convém à coisa por si. E por isso, concedo que deve ser questionada a causa da universalidade, entretanto, não deve ser questionada outra causa da comunidade que a própria natureza; e, colocada a comunidade na própria natureza mediante sua entidade própria e sua unidade, é preciso necessariamente questionar a causa da singularidade, que acrescenta algo àquela natureza da qual é." Cumpre ressaltar que as traduções do texto latino para o português são de nossa autoria.

${ }^{21}$ A unidade numérica é própria ao indivíduo, e não aceita divisão em partes subjetivas. Parte subjetiva denominase como a parte na qual está reproduzido o todo. Tome-se, por exemplo, o gênero animal. Cada espécie reproduz uma parte do gênero, contendo nela mesma o todo do gênero. Desse modo, a espécie ser humano, por exemplo, reproduz nela mesma o gênero animal, tal qual qualquer outra espécie animal; já o indivíduo reproduz nele aquilo que é próprio da espécie humana.

${ }^{22}$ As sete provas encontram-se nas seguintes passagens: $1^{\text {a }}$ prova) Lect. n. 13; Ord. n. 11; $2^{\text {a }}$ prova) Lect. n. 18; Ord. n. 16; $3^{\text {a }}$ prova) Lect. n. 21; Ord. n. 18; $4^{\text {a }}$ prova) Lect. n. 22; Ord. n. 19; $5^{\text {a }}$ prova) Lect. n. 23; Ord. n. 20; $6^{\text {a }}$ prova) Lect. n. 25; Ord. n. 28 (A $6^{\text {a }}$ prova da Lect. equivale a $7^{\text {a }}$ prova da Ord.); $7^{\text {a }}$ prova) Lect. n. 26; Ord. n. 23 (A $7^{\text {a }}$ prova da Lect. equivale a $6^{\text {a }}$ prova da $\operatorname{Ord}$.).

${ }^{23}$ Cf. DUNS Scotus. Lect. II, d. 3, p. 1, q. 1, nn. 23-24; Ord., nn. 20-21 (Por uma questão de brevidade, quando a passagem de Ordinatio for a mesma que a de Lectura, citaremos apenas o número dos parágrafos).

${ }^{24}$ Cf. DUNS Scotus. Lect. II, d. 3, p. 1, q. 1, n. 25; Ord., n. 28.
} 
intelecto apenas apreende a univocidade da coisa. Por exemplo, o fogo gera fogo por uma geração unívoca, o que torna o fogo gerado semelhante ao fogo gerador. A semelhança entre gerado e gerador requer uma unidade que não a unidade numérica, e essa unidade existe na realidade independente de qualquer intelecto. Há, portanto, uma unidade real menor do que a numérica.

Se toda unidade real fosse numérica, então toda a diversidade real seria numérica. ${ }^{25} \mathrm{Ou}$ seja, se toda unidade real fosse numérica, todas as coisas seriam igualmente diversas na realidade, e, consequentemente, não haveria algo comum entre indivíduos de uma mesma espécie. Dito de outra maneira, não seria possível abstrair algo mais comum entre dois indivíduos humanos do que entre um deles e qualquer outro objeto do mundo.

Por conseguinte, há uma unidade menor do que a unidade numérica, e essa unidade existe na realidade, independentemente do ato do intelecto. Uma vez que toda unidade acompanha uma entidade, ${ }^{26}$ é necessário que haja uma estrutura ontológica que possua a unidade real menor do que a numérica. Essa estrutura ontológica, para existir possuindo essa unidade, tem de se comportar de acordo com essa unidade, isto é, essa estrutura ontológica tem de ser capaz de estar em muitos. Ora, essas são justamente as características tradicionalmente atribuídas à natureza. Com efeito, ela é a estrutura ontológica capaz de ser replicada em cada indivíduo sem perder a sua estrutura original, e isso só é possível porque a natureza é dotada de comunidade.

Além disso, a comunidade permite que seja possível compreender a natureza enquanto conceito universal. Embora a natureza possa ser universalizada no intelecto, a natureza não é apenas uma construção conceitual universal. Tampouco é apenas singular na realidade. A natureza é o ser quiditativo da coisa, e responde a que conjunto um indivíduo pertence enquanto membro de uma espécie. É, assim, indiferente ao singular e ao universal, possuindo uma unidade própria a si. Consoante ao exposto, a natureza é, de si, apenas natureza, nem singular nem universal, tal qual, segundo Avicena, "equinidade é apenas equinidade, e não é, de si mesma, nem uma só nem muitas, nem universal nem singular". ${ }^{27}$

A natureza serve de estrutura tanto para o singular, uma vez que, ao ser contraída pela diferença individual, torna o singular este singular, quanto para o ato do intelecto a partir do qual se abstrai o que é comum aos membros de uma mesma espécie. Por ser uma estrutura, a natureza permite ao indivíduo possibilidades. Uma vez que a estrutura não diz o que a coisa é,

\footnotetext{
${ }^{25}$ Cf. DUNS Scotus. Lect. II, d. 3, p. 1, q. 1, nn. 26-27; Ord., nn. 23-27.

${ }^{26}$ Cf. DUNS Scotus. Lect. II, d. 3, p. 1, q. 6, n. 166; Ord., n. 169.

${ }^{27}$ DUNS Scotus. Lect. II, d. 3, p. 1, q. 1, n. 30. Cf. também Ord., n. 31
} 
mas sim, o que pode ser, a natureza assim pensada possibilita ao indivíduo realizar-se dentro de um campo de possibilidades.

\section{2 - Todo acidente é posterior à substância}

Refutada a possibilidade de a natureza ser tomada como princípio de individuação, o Doutor Sutil analisa outros candidatos, a saber: a dupla negação, na Questão 2; a existência em ato, na Questão 3; a quantidade, na Questão 4; e a matéria, na Questão 5; eliminando a todos.

A teoria da dupla negação, atribuída a Henrique de Gand, é eliminada como princípio de individuação. ${ }^{28} \mathrm{~A}$ dupla negação afirma que não há algo posto no indivíduo que o torne este indivíduo, mas ele o é por meio de duas negações. Ou seja, o indivíduo é numericamente um por ser indivisível em si mesmo e diferente dos demais. Contra, Duns Scotus argumenta que, se, em âmbito lógico, toda negação é uma afirmação de segunda ordem, isso se traduz ontologicamente por meio das perfeições. Dito de outra maneira, toda negação ontológica é a afirmação de uma incompossibilidade entre perfeições distintas. Assim, se é vetado ao singular ser divisível, isso só é possível se nele estiver presente uma perfeição responsável por sua unidade numérica. Ademais, uma negação não possui realidade ontológica, pois só pode se afirmar algo específico do indivíduo se houver algo nele na realidade. Uma negação pressupõe algo positivo no qual se funda, sendo necessário que haja o indivíduo primeiramente para que se negue algo acerca dele.

A teoria que afirma ser a existência atual aquilo que torna algo este indivíduo também é eliminada como causa da individuação. ${ }^{29}$ A existência não apenas não é exclusividade da coordenação predicamental da substância como perpassa toda essa coordenação predicamental. Por isso, tal qual a natureza, a existência não pode ser o elemento individualizante. A existência atual permite que cada indivíduo exista, mas não o torna este indivíduo, havendo, assim, primazia do ser de essência em relação ao ser de existência. Antes de algo ser este indivíduo, esse algo tem de poder ser este indivíduo.

A teoria da quantidade afirma que pelo indivíduo poder ser quantificado é a quantidade que o torna este indivíduo. ${ }^{30}$ Duns Scotus refuta a teoria da quantidade através de quatro vias, provando, nas três primeiras, que nenhum acidente pode ser a causa pela qual a substância

\footnotetext{
${ }^{28}$ Cf. DUNS Scotus. Lect. II, d. 3, p. 1, q. 2, nn. 39-53; Ord., nn. 43-58.

${ }^{29}$ Cf. DUNS Scotus. Lect. II, d. 3, p. 1, q. 3, nn. 54-60; Ord., nn. 59-65.

${ }^{30}$ Cf. DUNS Scotus. Lect. II, d. 3, p. 1, q. 4, nn. 61-124; Ord., nn. 66-128.
} 
material é singularizada, dedicando a quarta e última via para tratar da quantidade exclusivamente.

Na primeira via, a prova é a partir da singularidade. ${ }^{31}$ A substância material singular não pode ser modificada sem que se modifique o indivíduo. Se houver a modificação da substância material, haverá outra singularidade. A permanência da substância material independe de seus acidentes, portanto, os acidentes não podem ser a causa da permanência da substância e, consequentemente, da sua individuação.

Além disso, a teoria segundo a qual a quantidade é responsável pela individuação da substância material singular recai em uma contradição. Uma substância material singular não pode se modificar sem que haja uma mudança substancial. Afirmar que a quantidade é a responsável pela individuação significa afirmar que uma substância material singular foi modificada sem que houvesse uma mudança substancial. Dito de outra maneira, a mesma substância material singular tornar-se-ia outra substância material singular sem se modificar, o que é impossível.

Na segunda via, Duns Scotus prova a partir da ordem da substância em relação aos acidentes. ${ }^{32}$ A substância possui prioridade ${ }^{33}$ em relação aos acidentes segundo a sua natureza e sua coordenação. Por ser anterior a todo acidente no ser, nenhum acidente que vem depois pode ser o que determina a algo estar na coordenação. Ademais, o acidente só existe enquanto incidir sobre a substância, pois esta é a causa da existência dos acidentes. Portanto, algo posterior não pode ser a causa de algo anterior.

$\mathrm{Na}$ terceira via, a prova é a partir da razão da coordenação predicamental. ${ }^{34} \mathrm{~A}$ ordem predicamental requer um termo a partir do qual a coordenação tem início e um termo que é o seu fim. Como o último no gênero da substância é o singular desse gênero, o que torna algo individual tem de estar na categoria da substância, pois tudo o que pertence à ordem dentro da categoria tem de estar dentro da categoria. Aquilo que é próprio da substância material singular deve estar na categoria da substância, e, uma vez que a quantidade está fora da categoria da substância, não pode, portanto, ser aquilo que a individua.

Na quarta via, Duns Scotus prova especificamente contra o acidente da quantidade. ${ }^{35} \mathrm{~A}$ quantidade pode ser considerada sob duas perspectivas. De acordo com a primeira, é possível

\footnotetext{
${ }^{31}$ Cf. DUNS Scotus. Lect. II, d. 3, p. 1, q. 4, nn. 73-78; Ord., nn. 76-81.

${ }^{32}$ Cf. DUNS Scotus. Lect. II, d. 3, p. 1, q. 4, nn. 79-90; Ord., nn. 82-88.

${ }^{33}$ Duns Scotus argumenta a partir da teoria aristotélica segundo a qual há uma tripla primazia da substância em relação aos acidentes. Cf. ARISTÓTELES. Metaph. VII, 1, 1028b 30-35.

${ }^{34}$ Cf. DUNS Scotus. Lect. II, d. 3, p. 1, q. 4, nn. 91-94; Ord., nn. 89-98.

${ }^{35}$ Cf. DUNS Scotus. Lect. II, d. 3, p. 1, q. 4, nn. 95-106; Ord., nn. 99-110.
} 
falar em quantidade determinada, e isso significa a quantificação que dada substância possui de fato em dado momento. Mediante a segunda, pode-se falar em quantidade indeterminada. Essa quantidade indeterminada se refere à capacidade de ser quantificável característica de toda substância material na medida em que é material. A causa da individuação não pode ser a quantidade determinada, pois esta segue o ser da forma, completando a matéria. Ou seja, é um efeito e não a causa. Não poderia ser a quantidade indeterminada, pois, visto descrever apenas uma possibilidade de a substância material ser quantificada, ela, enquanto possibilidade de quantificação, permanece a mesma no gerado e no corrompido, o que faria com que ambos fossem o mesmo singular. Ademais, a quantidade enquanto quantidade é indiferente e, tal qual a natureza, não pode ser o que torna a substância material este indivíduo.

Não é possível, portanto, que algo ontologicamente posterior à substância a individue. Embora não haja o indivíduo sem os seus acidentes, visto que o acidente é o sine qua non da substância, os acidentes são consequência da individuação e não a sua causa, pois são posteriores a ela. Há primazia da substância em relação ao acidente.

A teoria que afirma ser a matéria a causa da individuação também é refutada. ${ }^{36} \mathrm{~A}$ teoria da matéria afirma que, uma vez que a forma é recebida na matéria, então, a matéria seria aquilo que faz com que algo seja este indivíduo. Duns Scotus a refuta como causa da individuação, pois a matéria é universalmente indiferente a muitos indivíduos. Ou seja, a noção de matéria deste ou daquele indivíduo é a mesma, pois a matéria é um conceito unívoco. Por ser passível de abstração, a matéria não pode ser aquilo que torna algo este indivíduo. É preciso algo real, intrínseco e positivo no indivíduo que o individue.

\section{3 - Diferença individual}

Embora os indivíduos de uma mesma espécie comunguem da mesma natureza, há algo exclusivo a cada indivíduo. É na Questão $6^{37}$ que Duns Scotus discute, a partir da tese de Godofredo de Fontaines, acerca da entidade intrínseca e positiva que faz com que algo se torne este indivíduo.

A substância material é individuada ao ter a sua natureza contraída por meio de algo positivo. Primeiramente, é preciso ter presente que há uma unidade da natureza específica e há uma unidade da singularidade. A unidade da natureza é a unidade real menor do que a unidade

\footnotetext{
${ }^{36}$ Cf. DUNS Scotus. Lect. II, d. 3, p. 1, q. 5, nn.125-138; Ord., nn. 129-141.

${ }^{37}$ Cf. DUNS Scotus. Lect. II, d. 3, p.1, q. 6; Ord., q. 6.
} 
numérica. Já a unidade da singularidade, à qual repugna ser dividida em partes subjetivas, é a unidade numérica. Devido a toda unidade seguir uma entidade, a unidade da natureza acompanha a entidade específica, e esta é responsável pela quididade da espécie. A unidade da singularidade possui uma entidade proporcional a si, ${ }^{38}$ a qual não pode ser a mesma que a unidade da natureza. É preciso, portanto, que a unidade da singularidade seja acompanhada por alguma entidade, que não a entidade da unidade da natureza. ${ }^{39} \mathrm{O}$ indivíduo é uno por si, consequentemente, a entidade da unidade da singularidade só pode ser algo positivo. ${ }^{40} \mathrm{O}$ elemento positivo por meio do qual a natureza específica é individuada é a diferença individual, ${ }^{41}$ e foi assim denominada por meio de comparação e semelhança à diferença específica. $^{42}$

A diferença individual é uma entidade positiva intrínseca à substância material, lhe sendo um elemento constitutivo e indissociável. A diferença individual é uma estrutura formal e não pode ser alcançada pelo intelecto do ser humano, pois este só compreende o universal. ${ }^{43}$ Ao contrair a natureza específica, uma vez que esta é indiferente à universalidade e à singularidade, a diferença individual torna algo este indivíduo. O indivíduo é, portanto, resultado da contração da natureza específica por meio da diferença individual, sendo uma composição das duas estruturas formais.

Da mesma maneira que a natureza específica, ao ser contraída pela diferença individual, gera o indivíduo, o gênero, ao ser contraído pela diferença específica, gera a espécie. Com isso, temos o gênero, a espécie e a diferença individual, sendo esta a atualização última da natureza de dado ente. Trata-se, então, de uma determinação real e positiva que confere ao ente ser distinto dos demais de sua espécie. A individualidade é a última realidade do ente, conferindo, assim, à diferença individual estatuto ontológico superior à natureza específica, pois, no mundo, somente o indivíduo singularizado existe. Destarte, o princípio de individuação scotista confere maior estatuto ontológico ao singular.

\footnotetext{
${ }^{38}$ Cf. DUNS Scotus. Lect. II, d. 3, p. 1, q. 6, n. 166.

${ }^{39}$ Cf. Ord. II. d. 3, p. 1, q. 6, n. 169.

${ }^{40}$ Cf. DUNS Scotus. Lect. II, d. 3, p. 1, q. 6, n. 166.

41 Diferença individual é o termo utilizado por Duns Scotus na Lectura e na Ordinatio para o princípio de individuação. A tradição scotista costuma utilizar o termo haecceitas. Cf. PÉREZ-ESTÉVEZ. 2008, p. 79.

${ }^{42}$ Cf. DUNS Scotus. Lect. II, d. 3, p. 1, q. 6, n. 169; Ord., n. 176.

${ }^{43}$ Cf. DUNS Scotus. Lect. II, d. 3, p. 1, q. 6, n. 180; Ord., n. 191.
} 


\section{4 - Distinção formal}

Como dito anteriormente, um princípio de individuação deve determinar o estatuto ontológico da individualidade respondendo três questões fundamentais: 1) há uma entidade individualizante que constitui o indivíduo ou isso é apenas uma construção mental?; 2) se há uma entidade individualizante, o que ela é?; 3) como são distintos o indivíduo e os demais componentes do indivíduo? O princípio de individuação formulado por Duns Scotus nos comprova que a entidade individualizante é algo intrínseco e positivo no indivíduo, e não é uma construção mental obtida através de um ato do intelecto. Ademais, o princípio scotista nos diz que a entidade individualizante é a diferença individual, a qual, ao contrair a natureza específica, torna algo este indivíduo. Respondidas as duas primeiras questões, resta-nos averiguar a terceira.

O indivíduo se constitui da contração da natureza específica por meio da diferença individual. A natureza específica fornece aquilo que é próprio à espécie, e a diferença individual fornece algo de exclusivo a cada indivíduo. A natureza humana, por exemplo, dá ao indivíduo humano aquilo que é comungado com os outros indivíduos da espécie humana. Já a diferença individual o caracteriza como único no mundo. Não houve e não haverá indivíduos iguais no mundo, pois a diferença individual fornece aquilo que é exclusivo a cada um deles.

Embora o indivíduo se constitua da contração da natureza específica por meio da diferença individual, ele é possuidor de unidade por si. Duns Scotus apresenta três possíveis maneiras de haver unidade: 1) a unidade entre coisas que são distintas, porém não encontramse distintas na realidade, por exemplo, matéria e forma ou corpo e alma; 2) a unidade entre coisas que são distintas segundo suas razões formais, sendo que uma razão formal inteira inclui a outra razão por meio da identidade, embora não formalmente, por exemplo, a unidade entre o indivíduo e a natureza específica ou entre o indivíduo e a diferença individual; e 3) a unidade entre diversas entidades formais que encontram-se na mesma coisa, em que uma não inclui a outra, nem uma é a outra por identidade, por exemplo, a unidade entre a natureza específica e a diferença individual. ${ }^{44}$ A terceira maneira é a unidade do indivíduo, pois a natureza específica e a diferença individual são duas formalidades que compõem o indivíduo.

O indivíduo é uma composição de duas formalidades distintas que o determinam. A unidade do indivíduo é possível porque a natureza específica e a diferença individual são duas entidades formais. Natureza específica e diferença individual não são dois entes distintos, uma

\footnotetext{
${ }^{44}$ Cf. DUNS Scotus. Lect. II, d. 3, p. 1, q. 6, n. 178.
} 
vez que não há uma diferença numérica entre ambas, mas são entidades formais que indicam aspectos reais do mesmo indivíduo. As duas entidades formais são estruturas com características diferentes, distinguindo-se entre si, e essa distinção denomina-se distinção formal.

A distinção formal é a distinção entre duas ou mais entidades formais que são indissociáveis na realidade, ${ }^{45}$ mas que geram, de si, razões distintas. Ou seja, a distinção formal é a distinção entre duas ou mais entidades formais que, enquanto estruturas, são diferentes, mas que não se constituem como coisas distintas, tal qual coisa e coisa, indicando aspectos distintos de uma mesma realidade. Porque são entidades formais distintas, o intelecto consegue abstrair razões diferentes, embora, na realidade, elas sejam indissociáveis. Porém, independentemente do ato do intelecto que as conhece, a distinção entre as entidades formais está na coisa. Dito de outra maneira, duas entidades são formalmente distintas quando, entre elas, há uma identidade real, pois elas não são numericamente diferentes, mas, a partir de suas quididades, o intelecto gera duas razões diferentes.

Entre natureza e diferença individual há uma identidade real e esta se configura como uma identidade do tipo $\mathrm{a}=\mathrm{b}$. Para Duns Scotus, há dois tipos de identidade: ${ }^{46} 1$ ) identidade de algo consigo mesmo, do tipo $\mathrm{a}=\mathrm{a}$, a qual se constitui em uma relação de razão; ${ }^{47}$ 2) identidade de algo em relação a outra coisa, do tipo $\mathrm{a}=\mathrm{b}$, a qual se constitui em uma relação real, e denomina-se identidade real. ${ }^{48}$ Mas, na medida em que 1) estamos falando de uma identidade que é real, e 2) que a identidade é uma relação, devemos analisar como Duns Scotus concebe esta noção, bem como a noção de "real".

Uma relação é dita real quando três requisitos são cumpridos, quais sejam: 1) o fundamento da relação e o termo final da relação têm de ser reais; 2) o fundamento da relação deve diferir realmente do termo fim da relação, e um extremo deve diferir do outro; e 3) a relação deve acompanhar o seu fundamento e o termo fim a partir da natureza da coisa. ${ }^{49}$ Por sua vez, para que uma relação seja dita de razão, basta apenas que um desses requisitos não seja cumprido. ${ }^{50}$

Consoante à noção de real, é no início da Ordinatio que podemos colher sua definição. ${ }^{51}$ "Real" (realis) e "realmente" (realiter) são termos relacionados à noção de coisa (res). Res é

\footnotetext{
${ }^{45}$ A realidade é o que existe no âmbito extramental, independentemente de qualquer intelecto que apreenda.

${ }^{46}$ Cf. DUNS Scotus. Lect. I, d. 31, q. un., n. 23; Ord., n. 18.

${ }^{47}$ Cf. DUNS Scotus. Lect. I, d. 31, q. un., n. 24.

${ }^{48}$ Cf. DUNS Scotus. Lect. I, d. 31, q. un., n. 25; Ord., n. 18

${ }^{49}$ Cf. DUNS Scotus. Lect. I, d. 31, q. un., n. 6; Ord., n. 6.

${ }^{50}$ Cf. DUNS Scotus. Lect. I, d. 31, q. un., n. 6; Ord., n. 6.

${ }^{51}$ Cf. DUNS Scotus. Ord. I, d. 2, p. 2, ad q. 1, n. 390.
} 
aqui compreendido como algo presente na realidade concreta, existindo por sua própria essência. Nesse sentido, "real" quer significar a característica de algo que existe extramentalmente de maneira tal antes mesmo que qualquer intelecto a considere. Dito de outra maneira, algo é dito "real" quando é ontologicamente tal, i.e., quando não é uma criação do intelecto que o considera.

Há, portanto, uma identidade real entre natureza e diferença individual, visto que a relação entre ambas se constitui em uma relação real. Para que possamos explicitar melhor, tenhamos em mente a relação entre natureza e diferença individual. $\mathrm{O}$ indivíduo deve ser entendido como o fundamento dessa relação e a diferença individual como o termo fim dela. Assim, a relação é real, pois 1) tanto o fundamento da relação (indivíduo) quanto o termo final (diferença individual) existem na realidade; 2) a natureza e a diferença individual são reais, mas não são idênticas; e 3) na relação, a natureza e a diferença individual são postas por meio da existência do fundamento da relação (indivíduo). Portanto, a relação entre natureza e diferença individual é uma relação real, havendo entre as duas entidades formais uma identidade real. Mas disso não se segue que a distinção entre elas seja uma distinção também real. Com efeito, em Ordinatio, Duns Scotus propõe um novo tipo de distinção, sendo esta uma originalidade sua e uma característica marcante da escola scotista, a saber: a distinção formal.

A distinção formal diferencia-se da distinção real e da distinção de razão. A distinção real é a distinção entre duas ou mais entidades que podem existir separadamente tanto no tempo quanto no espaço. Na medida em que essa distinção é caracterizada como real, a distinção real corresponde a algo no mundo extramental.

Por sua vez, tendo apresentado a distinção real, pode-se facilmente compreender o que seria uma distinção de razão. Com efeito, uma distinção de razão é aquela distinção posta na coisa pela ação do intelecto. Dito de outra maneira, uma distinção de razão não possui correspondência no mundo extramental. ${ }^{52}$

Passemos, pois, à distinção formal. Duns Scotus trata dessa distinção na segunda parte de Ordinatio I, distinção 2, mais precisamente em nn. 388-410. A distinção formal é uma distinção real, mas não no sentido atribuído pela tradição aristotélica. O ponto basilar consiste na defesa de que a identidade formal não se segue necessariamente da identidade real. ${ }^{53}$

A diferença formal vincula-se à diferença de definições. Quando uma mesma coisa gera dois conceitos diferentes e não mutuamente includentes, identifica-se uma identidade real, mas

\footnotetext{
${ }^{52}$ Cf. VOS. 2006, pp. 254-256.

${ }^{53}$ Cf. DUNS Scotus. Ord. I, d. 2, p. 2, ad q. 1, n. 408.
} 
uma distinção formal. Com efeito, no que é formalmente idêntico, as definições coincidem. ${ }^{54}$ A argumentação de Duns Scotus possui finalidade teológica. A natureza divina é comunicável, mas cada Pessoa da Trindade, não. Portanto, deve haver alguma outra identidade além da identidade real. Como visto anteriormente, a identidade do tipo $\mathrm{a}=\mathrm{b}$ é uma relação real, e Duns Scotus a atribui às Pessoas da Trindade. Contudo, as Pessoas divinas são distintas, mas estão necessariamente conectadas. Portanto, a não ser que haja a possibilidade de se verificar alguma distinção ex parte rei delas, não poderá haver relação real e, assim, não poderá haver identidade real entre elas.

Contudo, nem toda identidade real é também uma identidade formal. Se duas entidades são realmente idênticas pela identidade do tipo $a=b$, a diferença entre elas tem de ser uma diferença formal. ${ }^{55}$ Caso contrário, o segundo requisito para se ter uma relação real não seria cumprido. ${ }^{56}$

Como dito anteriormente, a natureza específica e a diferença individual se diferenciam por meio de uma distinção formal. As duas entidades formais compõem o indivíduo, indicando aspectos distintos de uma mesma realidade: a natureza específica é a estrutura comum compartilhada entre os membros de uma mesma espécie, e a diferença individual confere exclusividade a cada indivíduo. É impossível encontrar a natureza específica desvinculada do indivíduo. E o mesmo ocorre com a diferença individual.

Portanto, há no indivíduo duas entidades formais, natureza específica e diferença individual, que são distintas formalmente uma da outra, porém não é possível que sejam separadas como coisa e coisa. Sempre haverá a humanidade presente no indivíduo humano, por exemplo, sendo impossível encontrar a humanidade dissociada deste ser humano.

A distinção formal não é um mero distinguir conceitual, mas trata-se de um tipo de distinção real, pois é obtida a partir da realidade. Mas, na realidade, natureza específica e diferença individual não podem ser dissociadas uma da outra. A distinção entre ambas se configura entre os aspectos formais que constituem uma coisa. A distinção formal consiste em distinguir duas estruturas formais de uma mesma realidade. Ou seja, a coisa possui dois ou mais elementos distintos, e esses independem do ato do intelecto, pois são anteriores ao intelecto que os apreende.

\footnotetext{
${ }^{54}$ Cf. DUNS Scotus. Lect. I, d. 2, n. 275.

${ }^{55}$ Cf. DUNS Scotus. Ord. I, d. 2, p. 2, ad q. 1, n. 403.

${ }^{56}$ Cumpre ressaltar novamente que essa discussão tem por finalidade mostrar a viabilidade da Trindade. Com efeito, se houvesse uma distinção real do tipo coisa e coisa entre as Pessoas da Trindade, não haveria um Deus só, mas três deuses. Por sua vez, afirmar a existência de uma distinção de razão eliminaria a existência das três Pessoas. Assim, a única saída vislumbrada por Duns Scotus é afirmar uma identidade real entre as três Pessoas da Trindade, mas separando-as apenas formalmente, i.e., afirmar haver, entre elas, uma distinção formal.
} 
$\mathrm{Na}$ distinção formal, há o critério de separabilidade entre formalidades que geram, de si, razões diferentes. Isso indica a compreensão de que algo dotado de unidade real carece de unidade formal. Ou seja, algo dotado de unidade real é constituído por formalidades distintas, e, embora seja constituído por estruturas distintas, essas não podem ser separadas como coisa e coisa. Natureza específica e diferença individual são estruturas que não se encontram separadas no mundo, mas se distinguem formalmente uma da outra, pois a própria coisa gera no intelecto duas definições que não se incluem mutuamente. Há, entre a natureza específica e a diferença individual, uma relação de identidade real, acompanhada de uma distinção formal.

\section{Considerações finais}

O presente artigo se voltou à teoria da individuação formulada por João Duns Scotus. O princípio de individuação scotista nos permite compreender o que nos faz ser indivíduo e nos diferencia dos demais, nos possibilitando a reflexão acerca de como podemos compreender a constituição do sujeito. Ademais, o princípio de individuação scotista nos forneceu o arcabouço conceitual com o qual analisaremos as teorias de Sigmund Freud e de Edith Stein nos próximos estudos.

Como vimos, o princípio de individuação scotista não reduz o indivíduo a uma essência que o determina, mas nos permite compreender o ser humano como possuidor de uma estrutura que lhe permite possibilidades de ser. Como é sabido, na contemporaneidade, não se defende mais a existência de uma essência que determine o que é o ser humano. Assim, buscaremos averiguar se podemos pensar, em ambas teorias sobre as quais nossa investigação se voltará nos próximos estudos, no indivíduo humano como possuidor de uma estrutura ontológica que lhe forneça possibilidades de ser.

Neste primeiro estudo, tratamos dos conceitos de natureza e de diferença individual. A natureza é o ser quiditativo compartilhado entre os indivíduos pertencentes a uma mesma espécie. Já a diferença individual é também uma entidade inerente à substância material e indissociável dela. Ao contrair a natureza, a diferença individual torna algo este indivíduo. $\mathrm{O}$ indivíduo humano é resultado da unidade de duas formalidades, as quais the permite compartilhar algo com os demais da mesma espécie, bem como ser possuidor de algo exclusivo que o torna único e irrepetível. Ou seja, cada ser humano compartilha algo com todos os demais seres humanos, e isso o torna pertencente à espécie humana. Embora cada ser humano possua esse algo comum, há algo marcado no interior do seu ser que o torna único e irrepetível. 
Como mostramos, não é possível que aquilo que torna algo este indivíduo lhe seja ontologicamente posterior no ser. Assim, algo que seja ontologicamente posterior à substância não pode ser aquilo que a individua. Uma vez que os acidentes são posteriores à substância, os acidentes não podem ser aquilo que torna algo este indivíduo. Embora os acidentes sejam o sine qua non da substância, esses são a consequência da individuação e não a sua causa. Da mesma maneira, as identidades são o sine qua non da individuação, sendo consequência desta. Tal qual os acidentes acompanham a substância, as identidades acompanham o indivíduo, lhe sendo posteriores no ser. Há, portanto, anterioridade ontológica da individuação em relação à identidade. As identidades são indissociáveis do indivíduo, mas não o tornam este indivíduo, uma vez que são posteriores à individuação. Como resultado, "individuação" e "identidade" possuem conteúdos conceituais distintos. Constituição de indivíduo e constituição de identidade, embora tratados, muitas vezes, como sinônimos, indicam aspectos diferenciados de um mesmo sujeito. A constituição de indivíduo refere-se à individuação, e é ontologicamente anterior à constituição de identidade. A constituição de identidade é resultado de um processo que se dá ao longo do tempo.

Dito isso, uma teoria que tenha como objetivo compreender como se constitui o sujeito deve levar em consideração que 1) há algo compartilhado entre todos os indivíduos humanos; 2) embora haja algo em comum entre os seres humanos, há algo que confere exclusividade a cada um deles; e 3) o que confere exclusividade a cada indivíduo deve ser anterior àquilo que é desenvolvido posteriormente. Estes elementos serão utilizados para as investigações nos próximos estudos.

\section{REFERÊNCIAS BIBLIOGRÁFICAS}

ARISTÓTELES. Metafisicica. Edição bilingue (grego, português). São Paulo: Edições Loyola, 2005. v. 2.

AVICENA. Liber de philosophia prima sive scientia divina. Louvain: Peeters, 1977-1983. (3v).

DUNS Scotus, J. Opera omnia. Civitas Vaticana: Typis Vaticanis, 1950-. (v. 2 (1950): Ord. I, d. 2, p. 2, ad q. 1.v. 6 (1963): Ord. I, d. 31, q. un.; v. 7 (1973): Ord. II, d.3, p. 1, q. 1-6; v. 17 (1966): Lect. I, d. 31, q. un.; v. 18 (1982): Lect. II, d.3, p. 1, q. 1-6).

GRACIA, J. J. E. "Individuality and the Individualing Entity in Scotu's Ordinatio: Na Ontological Characterization" In: HONNEFELDER, L. et al. (orgs) John Duns Scotus: Metaphysics and Ethics. New York: E. J. Brill, 1996, pp. 229-249.

PÉREZ-ESTÉVEZ, A. "De Duns Escoto a Martin Heidegger". Veritas, 53/3 (2008), pp. 74-90. 
STROICK, C. "Eine Pariser Disputation vom Jahre 1306. Die Verteidigung des thomistischen Individuationsprinzips gegen Johannes Duns Scotus durch Guillelmus Petri de Godino O. P.”. In: W. P. Eckert (ed.). Thomas von Aquin: Interpretation und Rezeption. Mainz: Grünewald, 1974, pp. 559-608.

VOS, A. The Philosophy of John Duns Scotus. Edimburgo: EUP, 2006.

WOLTER, A. B. "Introduction". In: Early Oxford Lecture on Individuation. Saint Bonaventure, New York: The Franciscan Institute, 2005. pp. ix-xxi.

WOODWARD, K. "Identidade e diferença: uma introdução teórica e conceitual". In: SILVA, Tomaz Tadeu da (org.). Identidade e diferença: a perspectiva dos estudos culturais. Petrópolis: Vozes, 2011. p.7-72. 